Chronic Obstructive Pulmonary Diseases: Journal of the COPD Foundation

\title{
Original Research \\ Physiologic and Quantitative Computed Tomography Differences
Between Centrilobular and Panlobular Emphysema in COPD
}

Nicola Sverzellati, MD, PhD, ${ }^{1}$ David A. Lynch, MB, ${ }^{2}$ Massimo Pistolesi, MD, ${ }^{3}$ Hans-Ulrich Kauczor, MD, 4 Phillippe A. Grenier, MD, ${ }^{5}$ Carla Wilson, ${ }^{6}$ James D Crapo, MD; ${ }^{7}$ on behalf of the COPDGene ${ }^{\circledR}$ CT workshop group.

\begin{abstract}
Background: The purpose of this study was to define the differences between centrilobular emphysema (CLE) and panlobular emphysema (PLE) phenotypes in cigarette smokers with COPD by a combined qualitative-quantitative computed tomography (CT) analysis .

Methods: Chest CT scans of 116 cigarette smokers were visually scored by 22 chest radiologists and 29 pulmonologists in a single setting for the predominant emphysema phenotype (e.g. CLE or PLE) and automatically quantified for emphysema: percentage ratio of low attenuation area to corresponding lung area (LAA\%) $\leq-950$ Hounsfield Units

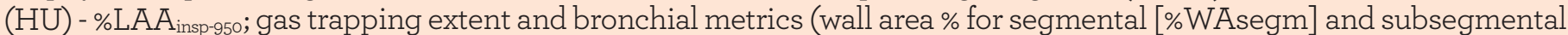
[\%WAsubsegm] bronchi). These quantitative CT indexes were compared and related to forced expiratory volume in 1 second (FEV1), ratio of FEV1 to forced vital capacity (FEV1/FVC), and smoking history as stratified for emphysema phenotype.

Results: Although more frequent than CLE in Global Initiative for chronic Obstructive Lung Disease (GOLD) stages 3 and $4(\mathrm{p}=0.01)$, PLE was also scored in $38.2 \%$ of combined GOLD stages 1 and 2. PLE was positively associated with $\% \mathrm{LAA}_{\text {insp-950 }}$ (odds ratio $[\mathrm{OR}]=1.18,95 \%$ confidence interval [CI]: 1.12 to $1.27, \beta$ coefficient $=0.17, \mathrm{p}=<0.0001$ ) and negatively associated with pack-years of smoking( $\mathrm{OR}=0.97,95 \% \mathrm{CI}$ : 0.95 to $0.99, \beta$ coefficient $=-0.02, \mathrm{p}=0.03)$. Both \%WAsegm and \%WAsubsegm were more strongly associated with FEV1\% $\left(\mathrm{R}^{2}=0.6\right.$ for both measures, $\left.\mathrm{p}<0.001\right)$ in CLE as compared to PLE $\left(\mathrm{R}^{2}=0.15, \mathrm{p}=0.02 ; \mathrm{R}^{2}=0.26, \mathrm{p}<0.001\right)$.

Conclusions: PLE likely represents a more advanced phase of emphysema, which may also occur in earlier COPD stages and show different interplay with airway disease as compared to CLE.
\end{abstract}

Funding Support: Supported by grants from the National Institutes of Health (Uo1 HLo89897 and U01 HLo89856, to COPDGene). Additional support is acknowledged from the COPD Foundation, AstraZeneca Inc, and GlaxoSmithKline Inc.

Date of Acceptance: March 13, 2014

Abbreviations: centrilobular emphysema, CLE; panlobular emphysema, PLE; computed tomography, CT; percentage ratio of low attenuation area to corresponding lung area, LAA\%; wall area percentage for segmental bronchi, \%WAsegm; wall area percentage for subsegmental bronchi, \%WAsubsegm; forced expiratory volume in 1 second, FEV1; forced vital capacity, FVC; Hounsfield Units, HU; Global Initiative for chronic Obstuctive Lung Disease, GOLD; odds ratio, OR; confidence interval, CI; quantitative CT, QCT; picture archiving and communications system, PACS; analysis of variance, ANOVA; body mass index, BMI;

Citation: Sverzellati N, Lynch DA, Pistolesi M, et al. Physiologic and quantitative computed tomography differences between cetrilobular and panlobular emphysema in COPD. J COPD F. 2014; 1(1):125-132.doi:http://dx.doi/org/10.15326/jcopdf.1.1.2014.0114

1 Department of Surgery, Section of Diagnostic Imaging, University of Parma, Parma, Italy

2 Division of Radiology, National Jewish Health, Denver, CO

3 Section of Respiratory Medicine, Department of Internal Medicine, University of Florence, Italy

4 Diagnostic and Interventional Radiology, University Clinic Heidelberg, Germany
5 Service de Radiologie Polyvalente, Diagnostique and Interventionelle, Hospital Pitie-Salpetriere, Paris, France

6 Division of Biostatistics and Bioinformatics, National Jewish Health, Denver, CO

7 Division of Pulmonary, Critical Care and Sleep Medicine, National Jewish Health, Denver, CO 


\section{Address correspondence to:}

Nicola Sverzellati, MD, PhD

Department of Surgery, Section of Diagnostic Imaging, University of Parma

Padiglione Barbieri, University Hospital of Parma

V. Gramsci 14, 43100, Parma, ITALY

Email: nicola.sverzellati@unipr.it

Tel number: +393384586715

\section{Keywords:}

emphysema; centrilobular; panlobular; computed tomography.

\section{Introduction}

Emphysema and small airway disease represent the major determinants of chronic airflow obstruction in smokers. ${ }^{1,2}$ The variable combination of these two main structural changes can be assessed by computed tomography (CT) analysis, which, in turn, may improve definition of chronic obstructive pulmonary disease (COPD) phenotypes. ${ }^{3-7}$ A number of CT-studies objectively quantified the global extent of emphysema, gas-trapping and bronchial metrics, and correlated them with functional, clinical and prognostic features..$^{8-11}$

Quantitative assessment of emphysema is most often based on the percentage of lung voxels below a specific threshold (density mask technique). These measurements can be performed globally for both lungs together or refined to an individual lung or lung region, ${ }^{12}$ and have been shown to be of relevance for surgical treatment planning and prognostication..$^{13-15}$ However, other emphysema features such as the gross morphology and the pattern distribution within the secondary pulmonary lobule do not lend themselves to quantitation using current available CT automated technique. Such additional structural information can be captured by the visual inspection which, despite its inherent subjectivity, might improve the definition of COPD phenotypes.

Radiologic-pathologic correlation studies showed that the different pathological phenotypes of emphysema centrilobular (CLE), panlobular (PLE), and paraseptal (PSE) emphysema - can be reliably distinguished on CT images. ${ }^{16,17}$ It has been shown that CLE increases with age and is more commonly observed in individuals older than 50 years, whereas PSE is more frequently observed among younger smokers. ${ }^{18}$ Previous studies showed that the frequency of CLE may overlap among smokers with and without COPD, whereas PLE is almost exclusively present in severe COPD. ${ }^{19}$ However, there is inconclusive data on the frequency of each emphysema pattern among COPD patients, especially for PLE not associated with alpha-1 antitrypsin deficiency ${ }^{19,20}$
The scarcity of radiologic data on the emphysema phenotypes is in contrast with that achieved by the pathologic studies. The latter suggest that CLE and PLE may be differently related to small-airway disease and airflow obstruction and that they may display different inflammatory changes. ${ }^{21-25}$ However, several questions on the significance of the emphysema phenotypes are still unanswered. It is unclear whether PLE is a more advanced stage of CLE or a completely different disease process. Furthermore, it would be interesting to understand whether $\mathrm{CT}$ can confirm noninvasively the correlations observed between pathologic changes and functional findings.

The aim of this study was to define the demographic, physiologic and quantitative CT (QCT) differences between CLE and PLE phenotypes of emphysema in smokers.

\section{Methods}

The research protocol was approved by the institutional review board at each participating institution, and all participants provided written informed consent. This study is based on quantitative and qualitative analyses performed on a population of 400 participants during an international, 4-day workshop held at the American College of Radiology Education Center (Reston, Virginia,). Workshop details can be found elsewhere. ${ }^{26}$

\section{CT and Visual Assessment of Emphysema Patterns}

Contiguous or overlapping axial sub-millimeter reconstructed CT slices were loaded on the picture archiving and communication system (PACS) server at the Education Center where 51 reviewers (29 pulmonologists, 22 radiologists) visually scored the $\mathrm{CT}$ images for several abnormalities by using a standardized electronic score sheet as previously described (further details also in the online supplementary material). ${ }^{26}$

The presence of emphysema was assessed by dividing the lungs into three zones (upper zone above the carina, mid zone between carina and inferior pulmonary veins, lower zone below the inferior pulmonary veins). Right and left lung were considered together. The score sheet recorded also the predominant pattern of emphysema (CLE or PLE) in upper, mid and lower zones. Global paraseptal emphysema was scored independently of CLE and PLE as follows: none, mild, moderate, severe.

\section{Study Participants}

This paper focuses on smokers with COPD and without alpha-1 antitrypsin deficiency, who had emphysema extent greater than $4.8 \%$ measured by QCT. Such a 
threshold corresponded to the goth percentile value for emphysema percentage in normal individuals. ${ }^{26}$ Therefore, individuals with QCT measurements exceeding this value were regarded as being affected by emphysema.

The median observer score was used for establishing the presence or absence of either CLE or PLE in each lung zone. Coexisting severe paraseptal emphysema was regarded as a potential confounding factor and these participants were therefore excluded from the study cohort. Individuals with any paraseptal emphysema who did not have CLE or PLE and individuals without visual evidence of emphysema were also excluded from the data analysis. Since participants could be scored as having more than one type of emphysema in different lung zones, predominant PLE and CLE patterns were defined as follows: individuals with CLE in any lung zone and none-to-moderate paraseptal emphysema were classified as having pure CLE; individuals with PLE in at least one of the three lung zones (regardless of the coexistence of CLE) and none-to-moderate paraseptal emphysema were classified as having PLE.

\section{Quantitative CT Analysis of Emphysema and Gas Trapping}

Quantitative analysis was performed on segmented lung images by trained analysts using the VIDA Pulmonary Workstation, version 2.O. For the whole lung as well as for each lung lobe, emphysema extent was defined as \% low attenuation area (LLA\%) less than or equal to -950 Hounsfield units $(\mathrm{HU})$ on inspiratory CT (\%LAA $A_{\text {insp-950). }}{ }^{27}$ Gas trapping percentage in nonemphysematous lung parenchyma was defined as the change in relative lung volume with attenuation values from -856 HU to -950 HU (\%RVC -856 to -950) between paired inspiratory and expiratory examinations. ${ }^{10,11}$ (Further details on RVC -856 to -950 are given in the online supplementary material.) In addition, expiratory-to-inspiratory ratio of mean lung density (EI-ratiomLD) was also calculated and presented as a percentage. ${ }^{28,29}$

For the distribution analysis, the right middle lobe was incorporated into the upper lobes. The ratio between the ${ }_{\text {\%AA }}$ insp-950 $_{\text {or }}$ \%RVC-856 to -950 for upper and lower lobes was used to define the distribution pattern of these parameter as follows: the distribution was considered upper lobe predominant if the result of the ratio was $>1$ and was considered diffuse or lower lobe predominant if it was $\leq 1.30$

The virtual airway tree was generated using an automated region-growing technique and detailed airway analysis to the subsegmental bronchi in 6 selected airway paths (RB1, RB4, RB10, LB1, LB4 \& LB10) was performed. The wall area \% (bronchial wall area as percentage of total bronchial area, \%WA) was calculated for segmental (\%WAsegm) and subsegmental bronchi (\%WAsubsegm) (see also online supplementary material).

\section{Data Analysis}

Inter-observer agreement for the assessment of CLE and PLE in the final study population was calculated by the multi-reader Kappa analysis. ${ }^{31}$ Comparative analyses were obtained using Student's unpaired, two-tailed t-test, the analysis of variance (ANOVA), Mann-Whitney U-test, or Chi-square test as appropriate to evaluate differences in selected demographic, functional and CT features across Global Initiative for chronic Obstructive Lung Disease guidelines (GOLD) stages and between CLE and PLE patterns. Logistic regression analysis was performed to assess the factors influencing the emphysema phenotype (with PLE as the dependent variable). Those factors that presented statistically significant differences in the bivariate analysis were included as the independent variables in the first step.

Spearman correlations were used to describe correlations among QCT indexes for CLE and PLE separately. Univariate and multivariate linear regression analyses were performed to investigate the relationship between FEV1\% of predicted, FEV1/FVC and QCT variables.

A $p$ value less than 0.05 was considered to be statistically significant. All statistical analyses were performed using MedCalc statistical software (version 9.5.2.0).

\section{Results}

A total of 116 out of 400 (29\%) cases met the study inclusion criteria. Comparisons of demographic, physiologic and QCT data stratified by the emphysema pattern are summarized in Table 1. Amongst the 61 cases with PLE predominant pattern, PLE was the only pattern scored in any of the 3 lung zones in 29 (47.5\%) cases, while PLE combined with CLE was scored in the remaining 32 (52.5\%). Mean kappa scores across reading groups for presence or absence of CLE and PLE were 0.16 and 0.3 , respectively.

All participants were white individuals. CLE and PLE individuals were similar for age and gender proportion. Individuals with CLE had a greater body mass index (BMI) and were heavier smokers as compared with those with PLE. Cases with PLE, compared with those with CLE, exhibited lower FEV1\% and FEV1/FVC, greater \%LAA $_{\text {insp-950, }} \%$ RVC $_{-856 \text { to }-950}, \%$ EI-ratio $_{M L D}(p=\leq 0.0001)$, 
Table 1. Participants' Characteristics Stratified for the Predominant Emphysema Phenotype.

\begin{tabular}{l|c|c|c} 
& $\begin{array}{c}\text { Predominant } \\
\text { CLE (n=55) }\end{array}$ & $\begin{array}{c}\text { Predominant } \\
\mathbf{P L E}(\mathbf{n = 6 3})\end{array}$ & p-valuea \\
\hline Age (mean \pm s.d.) & $66.8 \pm 7.4$ & $66 \pm 8.2$ & 0.4 \\
\hline BMI & $27.7 \pm 5.3$ & $25.2 \pm 5.3$ & 0.001 \\
\hline $\mathrm{N}(\%)$ male & $34(61.8)$ & $21(34.4)$ & 0.06 \\
\hline $\mathrm{N}(\%)$ current smokers & $11(20)$ & $7(6)$ & 0.3 \\
\hline Pack-years (mean \pm s.d.) & $64.5 \pm 30.6$ & $51.5 \pm 19.9$ & 0.007 \\
\hline FEV1\% (mean \pm s.d.) & $52.7 \pm 26.2$ & $35.5 \pm 19.5$ & $<0.0001$ \\
\hline FEV1/FVC (mean \pm s.d.) & 0.490 .13 & 0.370 .10 & $<0.0001$ \\
\hline$\% L A A_{\text {insp-950 }}$ & $14.7 \pm 7.3$ & $30.4 \pm 10.8$ & $<0.0001$ \\
\hline \%RVC.856to-950 & $-32.2 \pm 13.5$ & $-19.4 \pm 11.2$ & $<0.0001$ \\
\hline \%EI-ratiomid & $91 \pm 4$ & $94 \pm 3$ & 0.0001 \\
\hline \%WAsegm & $61.9 \pm 3.3$ & $62.1 \pm 3$ & 0.7 \\
\hline$\% W A s u b s e g m$ & $64.8 \pm 2.5$ & $65.6 \pm 2.4$ & 0.09 \\
\hline
\end{tabular}

${ }^{a} \mathrm{p}$-values from Student $\mathrm{t}$ test (for continuous parametric variables), Mann-Whitney U-test (for continuous nonparametric variables) or Chi-square test (for categorical variables) comparisons between CLE and PLE predominant groups.

but similar \%WAsegm and \%WAsubsegm ( $\mathrm{p}=0.09$ to 0.7). Cases with PLE, as compared to those with CLE, exhibited greater \% $\mathrm{LAA}_{\text {insp-950 }}$ and \% $\mathrm{RVC}_{-856 \text { to }-950}$ in each lobe $(p=0.03$ to $<0.0001)$. The distribution of \%LAA $A_{\text {insp-950 }}$

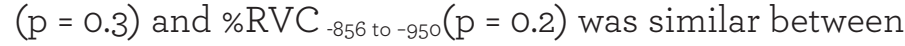
CLE and PLE: upper lobe predominant \%LAA ${ }_{\text {insp-950 }}$ was found in 51/55 (92.7\%) CLE and 52/61 (85.2\%) PLE cases

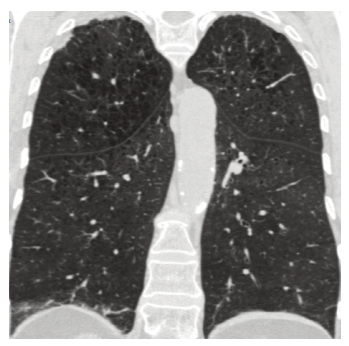

Fig.1- $\mathrm{A}$
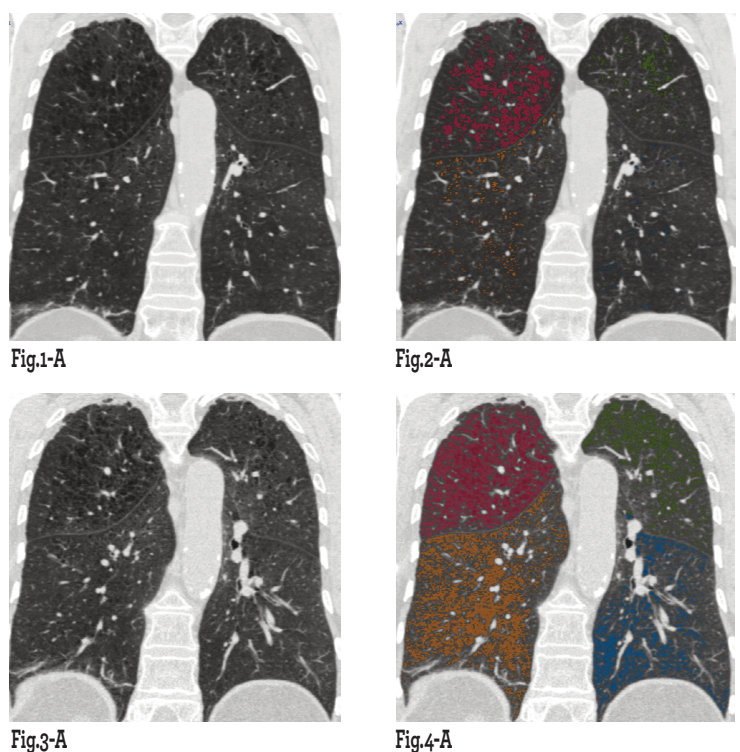

Fig.2- $\AA$

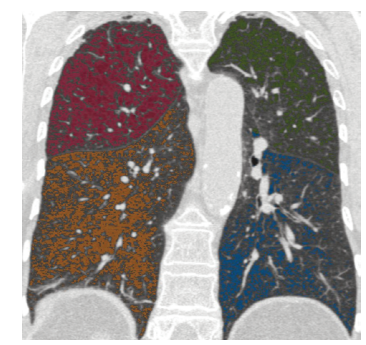

Fig. $4-\AA$

\section{Figure 1}

Automated depiction of emphysema and gas trapping in a 77- year-old female current smoker (60.8 pack years of smoking history) with GOLD 3 COPD. Fig.1-A Coronal reconstruction of volumetric inspiratory $\mathrm{CT}$ acquisition shows moderate upper lobe predominant emphysema. Fig1-B Density mask technique identifies low attenuation voxels less than or equal to -950 $\mathrm{HU}$ as emphysematous area (\%LAA $A_{\text {insp-950) }}$ ), which clearly predominate in the upper lobes. Different colors are assigned to different lobes. The ratio of \%LAA $A_{\text {insp-gso }}$ for upper vs. lower lobes was >1. Fig 1-C Coronal reconstruction of volumetric expiratory CT acquisition shows no evident low attenuation areas away from the emphysematous ones. Fig 1-D Density mask on the same image facilitates identification of voxels less than or equal to-856 $\mathrm{HU}$ diffusely distributed across upper and lower lobes. The ratio between the upper lobes and lower lobes change in relative lung volume with attenuation values from $-856 \mathrm{HU}$ to $-950 \mathrm{HU}\left(\% \mathrm{RVC} \mathrm{.r560}_{-050}\right)$ was $<1$.

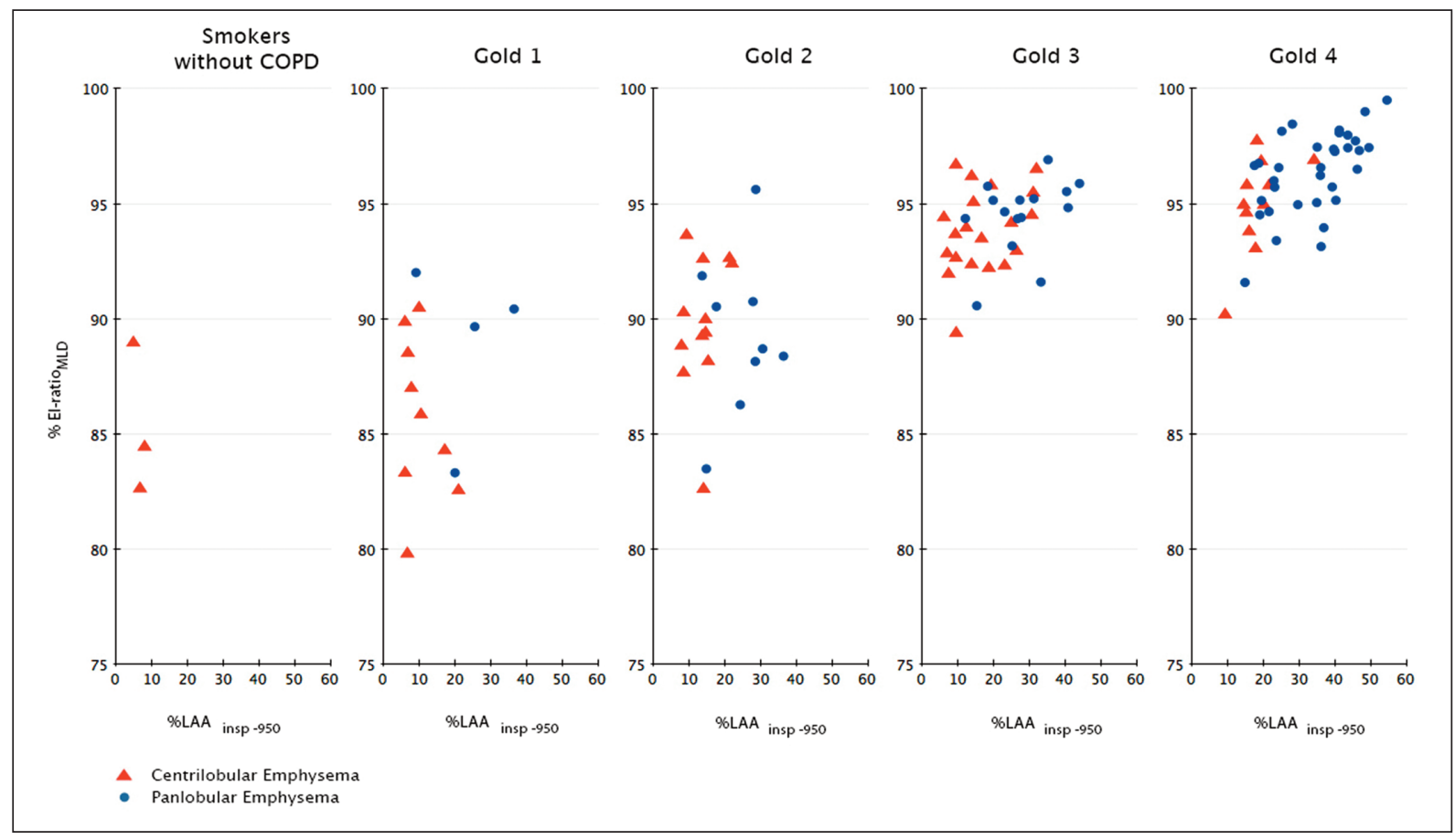

\section{Figure 2}

Distribution of cases with predominant centrilobular and panlobular emphysema across GOLD stages. Corresponding low attenuation area less than or equal to -950HU on inspiratory $\mathrm{CT}\left(\% \mathrm{LA} \mathrm{A}_{\mathrm{insp}-55}\right)$ and percentage expiratory-to-inspiratory ratio of mean lung density (\%EI-ratiomL) values are respectively reported on the $\mathrm{x}$-and $\mathrm{y}$-axis. 
Table 2 . Participants' Characteristics Stratified by COPD Severity.

\begin{tabular}{|c|c|c|c|c|c|c|}
\hline & $\begin{array}{c}\text { Smokers } \\
\text { without COPD } \\
(n=3)\end{array}$ & $\begin{array}{l}\text { GOLD 1 } \\
(n=13)\end{array}$ & $\begin{array}{l}\text { GOLD 2 } \\
(n=21)\end{array}$ & $\begin{array}{l}\text { GOLD } 3 \\
(n=35)\end{array}$ & $\begin{array}{l}\text { GOLD } 4 \\
(n=44)\end{array}$ & p-value ${ }^{a}$ \\
\hline Age & $58.2 \pm 3.7$ & $70.6 \pm 6.7$ & $65 \pm 8.4$ & $66.9 \pm 8$ & $65.9 \pm 7.4$ & 0.08 \\
\hline \multicolumn{7}{|l|}{ Gender } \\
\hline Male & 1 & 8 & 11 & 18 & 22 & \multirow{2}{*}{0.9} \\
\hline Female & 2 & 5 & 10 & 17 & 22 & \\
\hline $\mathrm{N}(\%)$ current smokers & $1(33.3)$ & $2(15.4)$ & $4(19)$ & $4(11.4)$ & $7(16)$ & 0.8 \\
\hline Pack-years & $36.7 \pm 5.3$ & $61.9 \pm 28.7$ & $60.8 \pm 27.2$ & $58.3 \pm 29.1$ & $55.3 \pm 23.2$ & 0.7 \\
\hline FEV1\% & $96.7 \pm 10.1$ & $88.4 \pm 7$ & $62.8 \pm 8.2$ & $38.5 \pm 6$ & $21.7 \pm 4.8$ & 0.03 \\
\hline CLE predominant & 3 & 9 & 12 & 20 & 11 & \multirow{2}{*}{0.0002} \\
\hline PLE predominant & 0 & 4 & 9 & 15 & 33 & \\
\hline \% LAA insp-950 $_{1}$ & $6.5 \pm 1.6$ & $14 \pm 9.4$ & $18.3 \pm 8.2$ & $21.6 \pm 10.5$ & $30 \pm 12$ & $0.002^{b}$ \\
\hline$\% \mathrm{RVC}_{-8560-950}$ & $-48.9 \pm 7$ & $-46.8 \pm 9.3$ & $-36.1 \pm 7.7$ & $-23.2 \pm 7.4$ & $-14.3 \pm 7.5$ & $<0.001^{\mathrm{c}}$ \\
\hline \%EI-ratiomLD & $85 \pm 3.2$ & $87 \pm 3.7$ & $89 \pm 3.1$ & $94 \pm 1.7$ & $96 \pm 1.9$ & $<0.001^{\mathrm{d}}$ \\
\hline \%WAsegm & $55.1 \pm 1.4$ & $59.2 \pm 2.8$ & $60.4 \pm 2.3$ & $62.9 \pm 2.1$ & $63.4 \pm 2.8$ & $<0.001^{\mathrm{e}}$ \\
\hline \%WAsubsegm & $61 \pm 1.1$ & $62.6 \pm 1.9$ & $63.3 \pm 1.7$ & $65.8 \pm 1.8$ & $66.7 \pm 2$ & $<0.001^{\mathrm{f}}$ \\
\hline
\end{tabular}

ap-values from Chi-square test (for categorical variables) or ANOVA (for continuous variables) analysis among GOLD stages.

${ }^{6}$ GOLD $4>$ GOLD 3, GOLD 2, GOLD 1, and smokers without COPD;

GOLD $4>$ GOLD $3>$ GOLD $2>$ GOLD 1 and smokers without COPD;

${ }^{\mathrm{G} G O L D} 4>$ GOLD $3>$ GOLD $2>$ GOLD 1 and smokers without COPD;

'GOLD 4 and GOLD $3>$ GOLD 2 and GOLD $1>$ smokers without COPD;

${ }_{\text {GOLD }}$ > GOLD $3>$ smokers without COPD, GOLD 1, GOLD 2 .

$(\mathrm{p}=0.1)$, whereas diffuse or lower lobe predominant \%RVC ${ }_{-856}$ to -950 was found in $43 / 55$ (78.2\%) of CLE and 40/61 (60.6\%) of PLE cases ( $\mathrm{p}=0.2$ ) (Fig. 1). At logistic regression analysis, only \%LAA $A_{\text {insp-950 }}(\mathrm{OR}=1.18,95 \% \mathrm{CI}$ : 1.12 to $1.27, \beta$ coefficient $=0.17, \mathrm{p}=<0.0001$ ) and pack-years of smoking ( $\mathrm{OR}=0.97,95 \% \mathrm{CI}$ : 0.95 to 0.99, $\beta$ coefficient $=-0.02, p=0.03$ ) were factors that respectively showed $\mathrm{a}$ direct and an inverse significant association with PLE.

Demographics, pulmonary function test results, smoking history and radiologic data of the study population are summarized against GOLD stages in Table 2. The frequency of CLE and PLE across GOLD stages was different $(p=0.0002)$, with PLE being strikingly more frequent in individuals with GOLD 4. Specifically, we found that PLE was more frequent than CLE in combined GOLD $3-4$ stages $(p=0.01)$, whereas PLE and CLE frequencies were not significantly different in smokers without COPD compared to GOLD 1-2 stages ( $p=0.3$ ). PLE was identified as the predominant pattern in 4/13 (30.8\%) GOLD 1 and 9/21 (42.8\%) GOLD 2 individuals; in these cases the median \%LAA $A_{\text {insp-950, }} \mathrm{RVC}_{-856 \text { to -950, }}$ $\%$ EI-ratio ${ }_{\text {MLD }}$ were respectively $25.5 \% \pm 8.6$ (median $\% \mathrm{LAA}_{\text {insp-950 }}$ in the whole study population $\left.=20.5 \%\right),-33.3 \%$ \pm 7.7 (median \% RVC -856 to-950 in the whole study population $=-23 \%$ ), and $89.6 \%$ (median \%EI-ratio MLD in the whole study population $=94.2 \%)$. All QCT indexes increased with increasing COPD severity (Fig. 2).

\section{Table 3. Univariate Linear Regression Analysis Between Quantitative CT Measurements and Pulmonary Function as Stratified for Predominant CT Emphysema Phenotype}

\begin{tabular}{|c|c|c|c|c|}
\hline & \multicolumn{2}{|c|}{$\begin{array}{l}\text { Predominant } \\
\text { CLE }\end{array}$} & \multicolumn{2}{|c|}{$\begin{array}{l}\text { Predominant } \\
\text { PLE }\end{array}$} \\
\hline & FEV1\% & FEV1/FVC & FEV $1 \%$ & FEV1/FVC \\
\hline$\% \mathrm{LA} A_{\text {insp-950 }}$ & $\begin{array}{c}0.2 \\
(p=0.0005)\end{array}$ & $\begin{array}{c}0.17 \\
(p=0.002)\end{array}$ & $\begin{array}{c}0.15 \\
(p=0.002)\end{array}$ & $\begin{array}{c}0.17 \\
(p=0.002)\end{array}$ \\
\hline$\% \mathrm{RVC}_{-856 \text { to-950 }}$ & $\begin{array}{c}0.75 \\
(p<0.0001)\end{array}$ & $\begin{array}{c}0.66 \\
(p<0.0001)\end{array}$ & $\begin{array}{c}0.48 \\
(p<0.0001)\end{array}$ & $\begin{array}{c}0.48 \\
(p<0.0001)\end{array}$ \\
\hline \%EI-ratio & $\begin{array}{c}0.72 \\
(p<0.0001)\end{array}$ & $\begin{array}{c}0.5 \\
(p<0.0001)\end{array}$ & $\begin{array}{c}0.61 \\
(p<0.0001)\end{array}$ & $\begin{array}{c}0.5 \\
(p<0.0001)\end{array}$ \\
\hline \%WAsegm & $\begin{array}{c}0.6 \\
(p<0.0001)\end{array}$ & $\begin{array}{c}0.56 \\
(p<0.0001)\end{array}$ & $\begin{array}{c}0.15 \\
(p=0.002)\end{array}$ & $\begin{array}{c}0.14 \\
(p=0.002)\end{array}$ \\
\hline \%WAsubsegm & $\begin{array}{c}0.6 \\
(p<0.0001)\end{array}$ & $\begin{array}{c}0.53 \\
(p<0.0001)\end{array}$ & $\begin{array}{c}0.26 \\
(p<0.0001)\end{array}$ & $\begin{array}{c}0.3 \\
(p<0.0001)\end{array}$ \\
\hline
\end{tabular}

Notes: Data are given as r-squared values $\left(R^{2}\right)$.

The correlations between \% $\mathrm{LAA}_{\text {insp-950 }}$ and \% $\mathrm{RVC}_{-856 \text { to }-950}$ or \%EI-ratiomLd were similar for both CLE $(r=0.54$, $\mathrm{r}=0.46$; both $\mathrm{p}<0.0001)$ and PLE $(\mathrm{r}=0.6, \mathrm{r}=0.4$; both $\mathrm{p}<0.0001)$.The correlations between \%LAA ${ }_{\text {insp-950 }}$ and either WAsegm or WAsubsegm were significant for CLE $(r=0.3, p=0.02 ; r=0.2, p=0.03)$, but not for PLE $(r=-0.2$, $\mathrm{p}=0.1 ; \mathrm{r}=-0.1, \mathrm{p}=0.4$ ). 


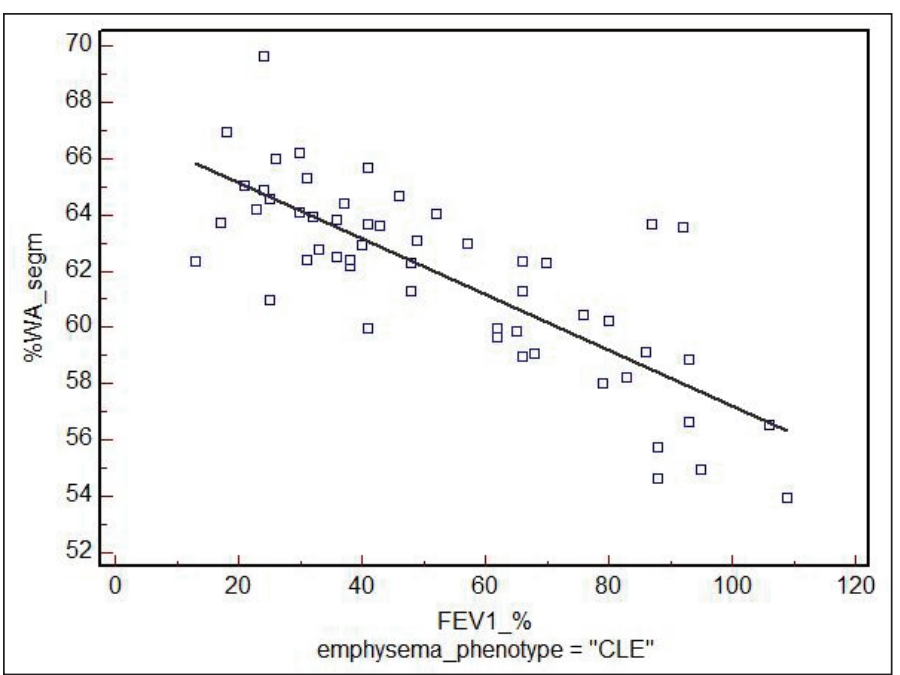

\section{Figure 3}

Relationship between percentage of segmental (\%WAsegm) and subsegmental wall area (\%WAsubsegm) and FEV $1 \%$ of predicted in centrilobualar (CLE) and panlobular emphysema (PLE). There are stronger relationships between \%WAsegm or \%WAsubsegm and FEV1\% in CLE $\left(R^{2}=0.6\right.$ for both \%WAsegm and \%WAsubsegm; $\left.p<0.001\right)$ than in PLE $\left(R^{2}=0.15\right.$ for \%WAsegm; $\mathrm{R}^{2}=0.26$ for \%WAsubsegm; $\mathrm{p}<0.001$.

Table 3 summarizes the univariate relationships between QCT indexes and both FEV1\% and FEV1/FVC. Most of these relationships were similar between the two emphysema phenotypes, but \%WAsegm and \%WAsubsegm were more strongly associated with both FEV1\% and FEV1/FVC in CLE $\left(\mathrm{R}^{2}=0.53\right.$ to $\left.0.6, \mathrm{p}<0.0001\right)$ as compared to PLE ( $\mathrm{R}^{2}=0.14$ to $0.3, \mathrm{p}=0.002$ to $\left.<0.0001\right)$ (Fig. 3). At multivariate analysis, both QCT gas trapping indexes and \%WAsegm largely explained the variability in both FEV1\% $\left(\mathrm{R}^{2}=0.79\right)$ and FEV1/FVC $\left(\mathrm{R}^{2}=0.71\right)$; the emphysema phenotype was not included in the predictive equation for both indexes (Table 4).

\section{Discussion}

Several observations support the hypothesis that CLE and PLE might represent different stages of the same disease in smokers: 1 ) whole-lung \%LAA insp-950 $_{\text {was }}$ greater

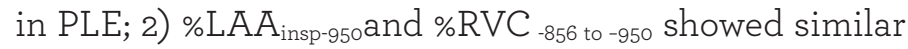
craniocaudal distribution in both CLE and PLE; 3) the prevalence and extent of PLE increased as COPD severity increased.

The relationships between FEV1\%, FEV1/FVC, \%LAA $A_{\text {insp-950 }}$ and either \%RVC-856 to-950 or \%EI-ratiomLD were also similar for CLE and PLE. Nevertheless, we reported different relationships between \%LAA $A_{\text {insp-950, }}$ FEV1\%, FEV1/FVC and bronchial metrics for CLE and PLE. Specifically, CLE displayed stronger associations between both \%WAsegm
Table 4. Results of Multivariate Linear Regression Analysis for Quantitative CT Measurements and Pulmonary Function Test Indexes as Dependent Variables.

\begin{tabular}{|c|c|c|}
\hline & $\begin{array}{c}\text { FEV1\% } \\
\left(R^{2}=0.79\right)\end{array}$ & $\begin{array}{l}\text { FEV1/FVC } \\
\left(R^{2}=0.71\right)\end{array}$ \\
\hline Emphysema phenotype & NS & NS \\
\hline$\%{ }^{2} A A_{\text {insp-950 }}$ & NS & -0.002 \\
\hline$\% \mathrm{RVC}_{-856 \text { to }-950}$ & -0.94 & NS \\
\hline \%EI-ratiomLD & -137.1 & -1.4 \\
\hline \%WAsegm & -1.7 & -0.06 \\
\hline \%WAsubseg & NS & -0.1 \\
\hline
\end{tabular}

Notes: Data are given as regression coeffcients ( $\beta$ coeffcient); NS = not signifcant

and \%WAsubsegm and the airflow obstruction indexes. This seems in line with previous pathologic, correlative studies that showed that in individuals with CLE, airflow obstruction was more closely related to small airway disease than to extent of emphysema whereas the opposite was true both for smoking-related and alpha-1 antitrypsin deficiency-related PLE. 6 ,21,23

Furthermore, weak but significant correlations were observed between \%WAsegm or \%WAsubsegm and \%LAA ${ }_{\text {insp-950 }}$ only in CLE. This finding is in keeping with that reported by Kim, et al, who found similar pathologic correlations between the emphysema extent and small airway wall thickening in CLE but not in PLE. ${ }^{22}$ It is possible that direct $\mathrm{CT}$ bronchial measurements, although more proximal, might better reflect the correlative pathologic findings as compared to CT indirect indexes of small airway disease (i.e. gas trapping).

Despite the greater prevalence of PLE in GOLD 3 and 4 stages, the distinction between PLE from CLE was a factor that did not sufficiently influence the disease functional impairment as suggested by the multivariate analysis of the present study. Aziz, et al, also reported no relation between FEV1 and CT pattern of emphysema (CLE or PLE). ${ }^{32}$ Importantly, a consistent proportion of our cases with PLE had mild to moderate COPD (38.2\% of combined GOLD stages 1 and 2 cases). This observation, as well as the negative relationship between PLE and pack-years of smoking and the greater prevalence of former smokers among individuals with PLE, suggests that some individuals with predominant PLE may have a stronger genetic susceptibility to emphysema or to a more rapid progression of the disease.

This study has several limitations. In keeping with prior studies, ${ }^{26,33}$ we obtained poor to fair inter-observer agreement levels for the visual identification of both CLE 
and PLE. Nevertheless, the final consensus was the median score of a large number of observers with diverse specialty training (chest radiology and pulmonary medicine), which may mitigate such scarce levels of agreement. We adopted strict classification criteria in order to identify relatively pure patterns of CLE and PLE, but this significantly reduced the size of our evaluable study population. Furthermore, although we excluded individuals with severe paraseptal emphysema, the coexistence of mild to moderate paraseptal emphysema (as categorized by the visual score) might have biased the differential analysis between CLE and PLE. Future studies might provide additional information by assessing the LAA size through the cluster analysis. This has been proven to be a better index for detection of terminal airspace enlargement that occurs in early emphysema and could be used to find other differences among the emphysema subtypes. ${ }^{34}$ A more complete functional assessment, including measurements of either carbon monoxide diffusing capacity or lung elastic recoil, would have improved the robustness of our findings. The low prevalence of current smokers in the study cohort made impossible a robust analysis of the relationship between smoking status and emphysema CT characteristics.

We conclude that the CT pattern of PLE represents a more advanced phase of emphysema, which may show QCT features and functional relationships different than CLE. We suggest that PLE may comprise several subtypes (particularly in mild disease) in smokers, thus highlighting that QCT and visual assessments should be combined to properly evaluate COPD.

\section{Acknowledgments}

Dr. Sverzellati had full access to all of the data in the study and takes responsibility for the integrity of the data and the accuracy of the data analysis. All the Authors contributed to the creation and final approval of this manuscript. Additionally, the members of the COPDGene ${ }^{\circledR}$ CT workshop group who visually evaluated the CT scans are as follows: R. Graham Barr, MD, DrPH, Eugene A. Berkowitz, MD, PhD, Francesca Bigazzi, MD, Frederick Bode, MD, Jessica Bon, MD, Russell P. Bowler, $\mathrm{MD}, \mathrm{PhD}$, Caroline Chiles, MD, James D. Crapo, MD, Gerard J. Criner, MD, Jeffrey L. Curtis, MD, Chandra Dass, MD, Asger Dirksen, MD, MS, Mark T. Dransfield, MD, Goutham Edula, MD, Leif Erikkson, MD, PhD, Maya Galperin-Aizenberg, MD, Warren B. Gefter, MD, David S. Gierada, MD, Jonathan Goldin, MD, PhD, Philippe A. Grenier, MD, MeiLan K. Han, MD, MS, Nicola A. Hanania, MD, MS, Nadia N. Hansel, MD, MPH, Francine L. Jacobson, MD, MPH, Hans-Ulrich Kauczor, MD, Vuokko L. Kinnula, MD, PhD, David A. Lipson, M.D., William MacNee, MBChB, MD, Barry J. Make, MD, A. James Mamary, MD, Howard Mann, MD, Nathaniel Marchetti, DO, Mario Mascalchi, MD, PhD, James R. Murphy, PhD, David Naidich, MD, Hrudaya Nath, MD, John D. Newell, Jr., MD, Massimo Pistolesi, MD, Elizabeth A. Regan, MD, $\mathrm{PhD}$, John J. Reilly, MD, Robert Sandhaus, MD, PhD, Joyce D. Schroeder, MD, Frank Sciurba, MD, Saher Shaker, MD, PhD, Amir Sharafkhaneh, MD, PhD, Edwin K. Silverman, MD, PhD, Robert M. Steiner, MD, Charlton Strange, MD, Nicola Sverzellati, MD, PhD, Joseph H. Tashjian, MD, Edwin JR van Beek, MD, PhD, Lacey Washington, MD, George R. Washko, MD, Gloria Westney, MD, MS, Susan A. Wood, PhD, Prescott G. Woodruff, MD, MPH.

Declaration of Interest: No conflict exists for any Author.

Role of Sponsors: The sponsors had no role in the design of this study, collection and analysis of data, or in the preparation of the manuscript. 


\section{References:}

1. Hogg JC. Pathophysiology of airflow limitation in chronic obstructive pulmonary disease. Lancet. 2004;364:709-721.

2. Pauwels RA, Buist AS, Ma P, Jenkins CR, Hurd SS. Global strategy for the diagnosis, management, and prevention of chronic obstructive pulmonary disease: National Heart, Lung, and Blood Institute and World Health Organization global initiative for chronic obstructive lung disease (GOLD), Executive summary. Respir Care. 2001;46: 798-825.

3. Han MK, Bartholmai B, Liu LX, et al. Clinical significance of radiologic characterizations in COPD. COPD. 2009;6(6):459-467.

4. Grydeland TB, Thorsen E, Dirksen A, et al. Quantitative CT measures of emphysema and airway wall thickness are related to dlco. Respir Med .2011;105:343-351.

5. Han MK, Kazerooni EA, Lynch DA, et al. Chronic obstructive pulmonary disease exacerbations in the copdgene study: Associated radiologic phenotypes. Radiology. 2011;261(1):274-282.

6. Kim WJ, Silverman EK, Hoffman E, et al. CT metrics of airway disease and emphysema in severe COPD. Chest. 2009;136(2):396-404.

7. Makita H, Nasuhara Y, Nagai K, et al. Characterisation of phenotypes based on severity of emphysema in chronic obstructive pulmonary disease. Thorax. 2007;62(11):932-937.

8. Kim V, Han MK, Vance GB, et al. The chronic bronchitic phenotype of copd: An analysis of the copdgene study. Chest. 2011;140(2):626633. doi: 10.1378/chest.10-2948.

9. Mets OM, Buckens CF, Zanen P, et al. Identification of chronic obstructive pulmonary disease in lung cancer screening computed tomographic scans. JAMA. 2011;306(16):1775-1781.

10. Mets OM, Murphy K, Zanen P, Gietema HA, et al. The relationship between lung function impairment and quantitative computed tomography in chronic obstructive pulmonary disease. Eur Radiol. 2012;22(1):120-128. doi: 10.1007/s00330-011-2237-9.

11. Matsuoka S, Kurihara Y, Yagihashi K, Hoshino M, Watanabe N, Nakajima Y. Quantitative assessment of air trapping in chronic obstructive pulmonary disease using inspiratory and expiratory volumetric MDCT. AJR Am J Roentgenol. 2008;190(3):762-769.

12. Lynch DA, Newell JD. Quantitative imaging of COPD. J Thorac Imaging. 2009;24:189-194. doi: 10.1097/RTI.obo13e3181b31cfo.

13. Cederlund K, Tylen U, Jorfeldt L, Aspelin P. Classification of emphysema in candidates for lung volume reduction surgery: A new objective and surgically-oriented model for describing CT severity and heterogeneity. Chest .2002;122(2):590-596.

14. Tanabe N, Muro S, Tanaka S, et al. Emphysema distribution and annual changes in pulmonary function in male patients with chronic obstructive pulmonary disease. Respir Res. 2012;13:31. doi: 10.1186/1465-9921-13-31

15. Johannessen A, Skorge TD, Bottai M, et al. Mortality by level of emphysema and airway wall thickness. Am J Respir Crit Care Med. 2013;187(6):602-608.

16. Bergin CJ, Muller NL, Miller RR. CT in the qualitative assessment of emphysema. J Thorac Imaging. 1986;1(2):94-103.

17. Foster WL, Jr., Gimenez EI, Roubidoux MA, et al. The emphysemas: radiologic-pathologic correlations. Radiographics. 1993;13(2):311-328.
18. Satoh K, Kobayashi T, Misao T, et al. CT assessment of subtypes of pulmonary emphysema in smokers. Chest .2001;120(3):725-729.

19. Gietema HA, Muller NL, Fauerbach PV, et al. Quantifying the extent of emphysema: Factors associated with radiologists' estimations and quantitative indices of emphysema severity using the ECLIPSE cohort. Acad Radiol. 2011;18(6):661-671.

20. Stavngaard T, Shaker SB, Bach KS, Stoel BC, Dirksen A. Quantitative assessment of regional emphysema distribution in patients with chronic obstructive pulmonary disease (COPD). Acta Radiol. 2006;47(9):914-921.

21. Kim WD, Eidelman DH, Izquierdo JL, Ghezzo H, Saetta MP, Cosio MG. Centrilobular and panlobular emphysema in smokers. Two distinct morphologic and functional entities. Am Rev Respir Dis. 1991;144(6):1385-1390.

22. Kim WD, Ling SH, Coxson HO, et al. The association between small airway obstruction and emphysema phenotypes in COPD. Chest. 2007;131(5):1372-1378.

23. Saetta M, Kim WD, Izquierdo JL, Ghezzo H, Cosio MG. Extent of centrilobular and panacinar emphysema in smokers' lungs: pathological and mechanical implications. Eur Respir J. 1994;7(4):664-671.

24. Linhartova A, Anderson AE, Jr. Small airways in severe panlobular emphysema: mural thickening and premature closure. Am Rev Respir Dis. 1983;127(1):42-45.

25. Ballarin A, Bazzan E, Zenteno RH, et al. Mast cell infiltration discriminates between histopathological phenotypes of chronic obstructive pulmonary disease. Am J Respir Crit Care Med. 2012;186(3):233-239.

26. Barr RG, Berkowitz EA, Bigazzi F, et al. A combined pulmonaryradiology workshop for visual evaluation of COPD: study design, chest CT findings and concordance with quantitative evaluation. COPD. 2012;9(2):151-159.

27. Gevenois PA, De Vuyst P, de Maertelaer V, et al. Comparison of computed density and microscopic morphometry in pulmonary emphysema. Am J Respir Crit Care Med. 1996;154(1):187-192.

28. Mets OM, Zanen P, Lammers JW, et al. Early identification of small airways disease on lung cancer screening CT: comparison of current air trapping measures. Lung. 2012;190(6):629-633.

29. Hersh CP, Washko GR, Estepar RS, et al. Paired inspiratory-expiratory chest CT scans to assess for small airways disease in COPD. Respir Res. 2013;14:42. doi: 10.1186/1465-9921-14-42.

30. Yuan R, Hogg JC, Pare PD, et al. Prediction of the rate of decline in FEV1 in smokers using quantitative computed tomography. Thorax .2009;64 (11):944-949.

31. Fleiss JL. Measuring nominal scale agreement among many raters. Psychol Bull. 1971;76(5):378-382.

32. Aziz ZA, Wells AU, Desai SR, et al. Functional impairment in emphysema: Contribution of airway abnormalities and distribution of parenchymal disease. AJR Am J Roentgenol. 2005;185 (6):1509-1515.

33. Copley SJ, Wells AU, Muller NL, et al. Thin-section CT in obstructive pulmonary disease: discriminatory value. Radiology. 2002;223(3):812-819.

34. Mishima M, Hirai T, Itoh $\mathrm{H}$, et al. Complexity of terminal airspace geometry assessed by lung computed tomography in normal subjects and patients with chronic obstructive pulmonary disease. Proc Natl Acad Sci U S A. 1999;96:8829-34. 